Published in (1998) 4 Legal Theory 283-300;

reprinted in Jules Coleman, ed,

Hart's Postscript: Essays on the Postscript to

'The Concept of Law' (Oxford University Press, 2001)

\title{
Herbert Hart and the Semantic Sting
}

\section{Timothy A.O.Endicott}

Even to disagree, we need to understand each other. If I reject what you say without understanding you, we will only have the illusion of a disagreement. You will be asserting one thing and I will be denying another. Even to disagree, we need some agreement. We need what Ronald Dworkin has called a 'fulcrum of disagreement' ${ }^{1}$ But it is a fulcrum of agreement as well, because we need to understand each other in order to agree. If I nod my head without understanding you, we will only have the illusion of an agreement. Whatever the fulcrum of disagreement is, we need it for any communication.

The most fundamental challenge that Dworkin has made to Hart's theory of law is that it cannot account for the nature of legal disagreement. This is the interpretivist challenge: (i) that Hart thought that the fulcrum of disagreement is a set of shared criteria for the application of legal concepts, and (ii) that we typically do not share such criteria. The challenge is so basic that, if it succeeds, genuine disagreement about the requirements of the law is impossible in Hart's theory. That itself would be a fatal objection to a theory of law. But the challenge is even more basic: if it succeeds, it shows that Hart's theory of law makes agreement and communication about the law illusory, because the fulcrum of agreement that the theory postulates is something that we do not share. That means that Hart's theory cannot explain how law accomplishes what Hart considered its basic function: to provide standards that guide behaviour.

Law's Empire presents an interpretive theory of law as an alternative to theories that suffer from a 'semantic sting'2 _ theories, that is, that 'insist that lawyers all follow certain linguistic criteria for judging propositions of law'. ${ }^{3}$ Dworkin claims that legal theories like Hart's cannot explain theoretical disagreement in legal practice, because they suffer from this semantic sting: they think that lawyers share uncontroversial tests ('criteria'4) for the truth of

\footnotetext{
1 'Hart's Posthumous Reply' (unpublished draft, September 1994) 14.

2 Law's Empire (Cambridge: Harvard University Press, 1986) 45. I will refer to Law's Empire as ' $L E$ '.

3 LE 32.

4 I will use the term 'criteria' in Dworkin's sense throughout, to refer to shared, uncontroversial tests for the application of a word.
} 


\section{Herbert Hart and the Semantic Sting}

propositions of law. If, like Hart, you suffer from the semantic sting, you think that the language of the law can be meaningful only if lawyers share such criteria. And then they cannot have any deep disagreement about the law. They can only disagree about how penumbral cases should be resolved, or about whether the law should be changed. To disagree about the criteria for application of the language of the law would be indistinguishable from not speaking the same language.

If 'semantic' simply means 'concerning meaning' (or even if it means 'concerning truth-conditions'), then Dworkin's argument cannot be that Hart makes semantic claims. Any non-sceptical theory of law needs to treat law as a practice that is carried on using meaningful language. No theory is less sceptical than Dworkin's. The argument has to be that Hart's semantic claims are misconceived. So we can redescribe Dworkin's distinction between interpretive theories and semantic theories as a distinction between theories that have an 'interpretive semantics' and theories that have a 'criterial semantics'. Dworkin is prepared to accept this clarification. ${ }^{5}$ He would now describe Hart's theory as an 'archimedean theory', or as a theory that misapplies 'criterial semantics' to legal concepts, rather than as a 'semantic theory'. But Dworkin does not claim that we never share criteria for the application of a word: his theory has the apparent virtue of allowing that different semantic theories might give the best account of the meaning of different words: criterial semantics for 'book', 'natural kind semantics' for 'tiger', and 'interpretive semantics' for 'law' (and presumably for most legal concepts). ${ }^{6}$ We can look at the semantic sting argument, then, as a claim that Hart applies criterial semantics to all legal (and, incidentally, jurisprudential) concepts, in a way that makes real disagreement about the law impossible.

In the face of this fundamental challenge, readers might expect Hart's 'Postscript' to defend a criterial semantic theory. But instead, Hart simply dismisses out of hand the allegation that he suffered from a semantic sting: 'nothing in my book or in anything else I have written supports such an account of my theory.' 7 Hart seems mystified by the allegation. He denies that he ever held the "mistaken idea that if the criteria for the identification of the grounds of law were not uncontroversially fixed, "law" would mean different things to different people' (246), and he claims to have drawn 'in effect the same distinction between a concept and different conceptions of a concept which figures so prominently in Dworkin's later work' (246).

Dworkin, in turn, is mystified by Hart's denial:

5 'I accept what might be called, I suppose, an interpretive semantics for law.' 'Hart's Posthumous Reply', supra note 1, 14.

6 Ib. 13-14.

7 H.L.A.Hart, The Concept of Law 2nd ed. (with a Postscript edited by Penelope A.Bulloch and Joseph Raz eds., Oxford: Clarendon, 1994) at 246. I will refer to The Concept of Law by page numbers in brackets. 


\section{Herbert Hart and the Semantic Sting}

So my discussion of this point must end in a kind of mystery. If I am wrong that Hart was a victim of the semantic sting, as he insists I am, then what can his motive have been for endorsing so counter-intuitive an account of legal disagreement, one which sharply curtails our natural sense of which disagreements are genuine? And if he did not adopt a criterial semantics for legal concepts, what did he think is the fulcrum of disagreement? ${ }^{8}$

I think that we can clear up these mysteries. There are turns of phrase in The Concept of Law and aspects of Hart's approach that encourage the notion that Hart had a criterial semantic theory. But it is a misinterpretation. The semantic claims that Hart actually made are simple and remarkably modest. I will argue that Hart did not have a criterial semantic theory-or any semantic theory at all, if a semantic theory is a general explanatory account of what makes an application of an expression correct. I will also argue that his theory can make sense of genuine theoretical disagreement. When we identify the claims that Hart makes we will see the answer to Dworkin's second question: to Hart, the fulcrum of disagreement is nothing more than the use of paradigms.

Paradigms also feature prominently in Dworkin's view of the fulcrum of disagreement. I will address the role of paradigms in The Concept of Law and Law's Empire, for the purpose of clarifying what each theory says about the meaning of words (sections 1 and 2). That discussion identifies a point of contention between Hart and Dworkin: can paradigms be indisputable? (section 3). Section 4 briefly discusses the important notion of 'pivotal cases' in Law's Empire, and uses it as a test for the competing claims about paradigms.

I conclude that a sound theory will reject criterial semantics-- but I doubt that anyone has ever had a criterial semantics. I also conclude that a sound theory cannot accept two distinctive claims of Law's Empire: that no paradigm of an abstract concept is secure from the interpretive process, and that abstract words are not vague.

\section{The modesty of Hart's semantic claims}

Why is it so tempting to think that Hart has a criterial semantic theory? To some extent, the reasons are atmospheric. He calls his book The Concept of Law. He confesses in his Preface to addressing 'questions which may well be said to be about the meaning of words' (v), and he twice quotes J.L.Austin's comment about 'using a sharpened awareness of words to sharpen our perception of the phenomena' $(\mathrm{v}, 14)$. In cases of the open texture of a general term, he says, "no firm convention or general agreement dictates its

8 'Hart's Posthumous Reply', supra note 36, 15. 


\section{Herbert Hart and the Semantic Sting}

use' (127), suggesting that a firm convention or general agreement dictates the use of general terms in other cases. If 'vehicles' are banned from the park, he says that 'the language used in this context fixes necessary conditions which anything must satisfy if it is to be within its scope' (128-9) (and he seems to extend the same claim even to highly contestable legal concepts like 'fair rate' or 'safe systems' of work (131)).

All this would support the claim that Hart thinks that the fulcrum of legal disagreement is a set of shared, uncontroversial criteria for the correct application of the word 'law'. Except that he rejects that notion.

Consider a dilemma that Hart would face if he had a criterial semantic theory. Imagine that an anthropologist returns from a trip to Freedonia, and says to Hart, 'you'd be interested in the legal system of Freedonia. Their law consists entirely of primary rules.' Here's the dilemma: The Concept of Law finds 'the key to the science of jurisprudence' in the union of primary and secondary rules (81). It seems that Hart has to say that his friend the anthropologist has made not just a bad mistake, but a bizarre sort of mistake: she is not using the words 'law' and 'legal system' in accordance with the rules for their use. She is not even speaking English. But whatever her qualities as a legal theorist, it seems absurd to question her grasp of her mother tongue.

In fact, Hart did not think that there was any dilemma here at all. In the situation we have imagined, he would not set out to teach the anthropologist English. Nothing in The Concept of Law even gives him a reason to correct her. He thought that he could distinguish between 'elucidating the concepts that constitute the framework of legal thought' (81) (which he was trying to do) and identifying rules for the use of words (which he was not trying to do):

We shall not indeed claim that wherever the word 'law' is 'properly' used this combination of primary and secondary rules is to be found; for it is clear that the diverse range of cases of which the word 'law' is used are not linked by any such simple uniformity, but by less direct relations - often of analogy of either form or content - to a central case. (81)

This passage does not make an off-hand caveat; it states three features of Hart's approach that are consistently articulated throughout The Concept of Law: (i) that he is not giving rules for the correct use of words, ${ }^{9}$ (ii) that there may be no shared, uniform test for the extension of a concept, and (iii) that we can say no more in general terms about the extension of a concept than that its instances are linked by relations to central cases - to paradigms. Those relations cannot themselves be described in the form of a criterion or set of

\footnotetext{
${ }^{9} \mathrm{Cf}$. (17): 'its [the book's] purpose is not to provide a definition of law, in the sense of a rule by reference to which the correctness of the use of the word can be tested'. See also (209).
} 


\section{Herbert Hart and the Semantic Sting}

criteria. They may be relations of analogy, and analogy is not a shared uncontroversial test of application.

The most important statement of this manifesto is Hart's account in Chapter I of the limited usefulness of the traditional form of definition per genus et differentiam. If that form of definition gave a model for the meaning of an expression, it would yield criterial semantics: to know the meaning of a word would be to know its genus and also the characteristics that speakers use to distinguish its instantiations from instantiations of other species of the same genus. That is the notion that Hart rejects:

The supposition that a general expression can be defined in this way rests on the tacit assumption that all the instances of what is to be defined as triangles and elephants have common characteristics which are signified by the expression defined. Of course, even at a relatively elementary stage, the existence of borderline cases is forced upon our attention, and this shows that the assumption that the several instances of a general term must have the same characteristics may be dogmatic.

All that Hart is claiming about concepts is that their instances must be linked together by resemblances to 'plain indisputable cases' (131), to 'the clear standard case or paradigm for the use of an expression' (4), to 'paradigm, clear cases' (129). But 'the several instances of a general term are often linked together in quite different ways from that postulated by the simple form of definition' (16).

For Hart, as for Wittgenstein, the fulcrum of disagreement is 'general agreement in judgments' in familiar cases (126) ${ }^{10}$. 'General terms would be useless to us as a medium of communication unless there were such familiar, generally unchallenged cases.' (126) That claim about meaning is important to Hart, but it is no part of a semantic theory, because it does not support any explanation of what makes an application of a word correct (except the nontheoretical proposition that the word applies to objects that are sufficiently similar to paradigms). It does not claim that we share criteria of applicability. He would view that sort of claim as dogmatic. The fulcrum of agreement and disagreement, in this view, is nothing more than the use that is made of a set of paradigms of the concept in question: their use as standards of comparison.

There are two possible objections to characterising Hart's semantic claims as modest in this way: (1) that I have made them look more modest than they are, and (2) that they are still too immodest - that Hart proposes, as the

10 Cf. the reference at (297) to Wittgenstein, Philosophical Investigations sections 208-238. At section 208 Wittgenstein writes, '...if a person has not yet got the concepts, I shall teach him to use the words by means of examples and practice.-And when I do this I do not communicate less to him than I know myself.' 


\section{Herbert Hart and the Semantic Sting}

fulcrum of agreement and of disagreement, a form of agreement that we do not have and do not need.

(1) The modest characterisation of Hart's claims may seem inaccurate, because he does discuss tests for and, characteristics, features... of the instantiations of concepts. We may ask, aren't those all just criteria for the application of concept-words? Take the concept of law. The burden of Hart's book is to elucidate that concept, and he does not stop at pointing to examples. Indeed, he starts by insisting that people in general know examples of laws, and standard cases of legal systems (4), and he asks whether we should answer the question 'what is law?' by simply appealing to their knowledge and saying, "such is the standard case of what is meant by "law" and "legal system", and reminding them that there may be borderline cases. He rejects that approach as unhelpful. But his alternative is not to give criteria of applicability of 'law' that he claims we share. His alternative is to stop and ask what particular puzzles we face when we ask 'what is law?', and to address those puzzles by pointing out and describing those features of the clear cases that he judges to be salient and useful for resolving the puzzles. The features he proposes are his account of the nature of social rules, and his account of what is distinctive about legal rules (the union of primary and secondary rules, and in particular the role of rules of recognition).

But don't those very elements of Hart's theory of law amount to a set of criteria for the application of the word 'law'? Not in the sense required by the allegation that he has a criterial semantic theory: he insists that you do not need to follow his theory to use the word correctly, and he never claims that English-speaking people share the view that the features he identifies are criteria for the application of the word 'law'. ${ }^{11}$ He never claims that his theory of law is true by definition, or that anyone who understands the word 'law' will agree with him in virtue of their understanding. His claims always remain vulnerable to an argument that the characteristics of law that he identifies are not actually features of what goes on in an ordinary sort of municipal legal system, or that he has misdescribed them, or they are not salient in the way he thinks....

There is another feature of Hart's theory of law that might encourage the view that he analyses the meaning of a concept-word as consisting in a set of criteria for its application. His analysis of the concept of law yields the claim that a community with law has a rule of recognition-a social rule which provides criteria of legal validity. Those criteria determine the law, to the extent that it is determinate (see e.g. 94-5, Ch.VI.1, 148). But it would be a misinterpretation of Hart to take him to be proposing that the meaning of the word 'law' consists of a set of criteria for identification of laws in a

11 He does claim that the officials of a legal system share criteria of legal validity (and his theory, though not his account of the meaning of the word 'law', is vulnerable if that claim cannot be supported). But those criteria are not semantic: see text below. 


\section{Herbert Hart and the Semantic Sting}

community. His claim is that, in the central case of a legal system, officials follow a social rule that provides such criteria. Those criteria are not criteria for the application of the word 'law', though they do identify the law of the community. There is nothing semantic about the criteria of legal validity: rules providing that higher courts' decisions bind lower courts, that legislation binds ministers, and so on, are not semantic rules. Hart claims that Dworkin has misunderstood him in this way-that Dworkin ignores the distinction between statements 'of what "law" is' and statements 'of what the law is, i.e. what the law of some system permits or requires or empowers people to do' (247). To Hart, rules of law are not (and are not derived from) rules for the use of the word 'law'.

Hart thinks that there are indisputable paradigms, and that is all there is to his semantic claims. Or rather, he makes no claim that we need, or share, more agreement than can be captured in the proposition that the instantiations of a concept must be sufficiently similar to paradigms in relevant respects. Not that Hart thinks that there is anything magical about paradigms: we can explain the meaning of concept-words with or without reference to paradigms. We can explain meaning by giving accounts of the characteristics of instantiations of the word, just as well as we could by pointing to examples. But those accounts will not carry more information than we could convey by explanations that refer to paradigms. They will not report shared criteria of application any more stringent than we would provide if we pointed to paradigms.

On this modest view of Hart's claims about the application of a conceptword, he only claims to be pointing out important features of plain indisputable cases of the concept. An apparent counter-example to this view is Hart's talk of two 'necessary and sufficient conditions' for the existence of a legal system: general obedience by citizens and effective acceptance by officials (116). Acceptance by officials is, he says, 'logically a necessary condition of our ability to speak of the existence of a single legal system'. That certainly reads as if he is giving a rule for the correct use of the phrase 'legal system': he is claiming that nothing less than his two conditions would suffice for that phrase to apply, and no more can be required. If the modest view of Hart's semantic claims is right, you might say, he should have talked of characteristic features of paradigm cases of legal systems, and not of necessary and sufficient conditions for speaking of a legal system.

I think that a charitable interpretation of Hart will take this passage in the following way. His concern there was to develop an account of acceptance of the rule of recognition. He wanted to insist that acceptance by citizens is not required, because he thought that, if a legal regime were imposed on a populace by force, it would still be relevantly similar to paradigm municipal legal systems. He also wanted to insist that acceptance by officials is required, because without it, 'the characteristic unity and continuity of a legal system would have disappeared' (116). Acceptance by officials of a rule of recognition is not a criterion of law required by a rule for the use of the word 


\section{Herbert Hart and the Semantic Sting}

'law'; it is a condition for the existence of a characteristic feature of paradigm legal systems. Even if Hart's claim is true, official acceptance is 'logically a necessary condition' just in the sense that, without general official acceptance of a rule of recognition, a characteristic feature of paradigm legal systems would be missing. On this interpretation, the passage is consistent with the modest view of Hart's semantic claims; his desire to contrast acceptance by officials from acceptance by citizens led him to use the misleading phrase 'necessary and sufficient conditions'. A similar approach to the interpretation of Hart could deal with his comment that, in a prohibition on 'vehicles', 'the language used in this context fixes necessary conditions which anything must satisfy if it is to be within its scope' (129). I am proposing that, in Hart's theory, those 'conditions' simply have the same content as a requirement that the thing in question must be similar in relevant respects to paradigm vehicles.

So all that Hart claims that people share concerning a concept like law is the ability to identify 'examples of law', and the idea that there are different legal systems in different countries, and an ability to identify salient points of similarity among legal systems. People can articulate those similarities in something like the following 'skeleton way':

They comprise (i) rules forbidding or enjoining certain types of behaviour under penalty; (ii) rules requiring people to compensate those whom they injure in certain ways; (iii) rules specifying what must be done to make wills, contracts or other arrangements which confer rights and create obligation; (iv) courts to determine what the rules are and when they have been broken, and to fix the punishment or compensation to be paid; (v) a legislature to make new rules and abolish old ones. (3)

Now, the claim that Hart has a criterial semantics might seem to be borne out by this set of features of a municipal legal system, which appear to amount to a set of criteria for application of the word 'law' or of the phrase 'legal system'. But Hart is not even committed to the claim that English speakers share the understanding that these are features of law (he says that he put this account 'perhaps optimistically... into the mouth of an educated man' (5)). More importantly, look at what the account amounts to. We can cross out the word 'rule' which, since Dworkin wrote 'The Model of Rules', ${ }^{12}$ has carried theoretical baggage that Hart did not have in mind. Read Hart's account to say that 'legal systems (i) forbid or enjoin...; (ii) require people...; (iii) specify...; (iv) have courts...; (v) have a legislature...'. If that is all that Hart's theory provides in the way of shared criteria for application of 'law', it does not support the claim that he had a criterial semantics for such concepts: those features of law are, again, simply the least controversial sorts of statements that can be made about paradigm legal systems. We share the view that these

12 TRS Chapter 2. 


\section{Herbert Hart and the Semantic Sting}

are features of law, but that is no more than to say that we share a set of paradigms, and these are obvious (and obviously important) features of the paradigms. In Hart's view, we can come to understand the concept better by developing a more searching account (an account that is not generally shared by English speakers) that addresses and resolves a particular puzzle about the concept. The standard of success for that account will not be that it provides 'correct tests for applying some word' ( $L E 41)$, or that it is uncontroversial: Hart was all too aware, throughout his career, that his theory of law was controversial. The standard of success will be that it addresses the puzzle in question, and is a faithful account of the paradigms. Such an account will leave ample room for uses of the term that are analogous, metaphorical, or, in Finnis's Aristotelian term, homonymous. ${ }^{13}$

(2) If the modest interpretation of Hart is right, he still retains the basic, controversial claim that paradigms are indisputable. It may seem that Hart's account as I have characterised it still supposes too much agreement of the wrong sort. That charge calls for a closer look at Dworkin's interpretivist claim that paradigms can be eradicated.

\section{Dworkin on Paradigms}

Paradigms anchor interpretations, but no paradigm is secure from challenge by a new interpretation that accounts for other paradigms better and leaves that one isolated as a mistake. ( $L E 72)$

To Dworkin, paradigms are part of the preinterpretive material on which an interpreter goes to work. That is, they are part of what a successful interpretation (in fact, 'any plausible interpretation' $-L E 72$ ) must fit. But no single paradigm is guaranteed to emerge intact from the post-interpretive stage, at which the interpreter "adjusts his sense of what the practice "really" requires so as better to serve the justification he accepts at the interpretive stage' ( $L E$ 66). No eligible interpretation could abandon all the paradigms, but no individual paradigm is safe: for an interpretation to be eligible is for it to fit some proportion of paradigms. And an interpretation that ousts a particular paradigm can only do so by accounting better for other paradigms than any interpretation that retains the ousted paradigm.

Paradigms of interpretive concepts are different from 'cases in which, as philosophers say, a concept holds "by definition", as bachelorhood holds of unmarried men' ( $L E 72$ ). No paradigm of an interpretive concept is secure.

13 See Natural Law and Natural Rights (Oxford: Clarendon, 1980) 9-11 on the ways in which theoretical (and presumably other) terms may be applied homonymously, or by analogies to central cases. 


\section{Herbert Hart and the Semantic Sting}

The same point can be framed in terms of Dworkin's distinction between concepts and conceptions. Dworkin claims that the expressions used to set out fundamental rights in a constitution, such as 'equal' and 'cruel', are not vague, but abstract, and represent appeals to contested concepts that admit of different conceptions. To apply such an expression it is never enough to be familiar with the concept and the facts. You must also develop a conception of the concept. In Dworkin's theory, no legal indeterminacy arises from the use of such concepts, because there is always a best conception of a contested concept. ${ }^{14}$

Law's Empire uses the concept of courtesy as an example of an abstract concept. Any member of the community will know of paradigms of courtesy. But no paradigm is secure. Picture a paradigm of courtesy: that men should stand when a woman enters a room ( $L E 72)$. A new interpretation of the practice of courtesy might oust that paradigm, and conclude that it is not courteous for men to stand when a woman enters the room. And such a paradigm-ousting interpretation would not be a proposal to change the requirements of the practice, but a conclusion as to what those requirements really are. So where Hart might say that possessing a concept entails knowing that it applies to a paradigm case, Dworkin sees no such connection. Dworkin's theory denies that abstract words have any application that is independent of theory-building: every question of the application of an abstract concept-word is an interpretive question.

We have seen that Hart's Postscript associates a concept with the meaning of a concept-word, and a conception with its application. He claims that Dworkin accused him of confusing 'the meaning of a concept with the criteria for its application.' (246) Denying that he had suffered from that confusion, he writes, 'I drew in effect the same distinction between a concept and different conceptions of a concept which figures so prominently in Dworkin's later work.' $(246)^{15}$

If we are to make sense of Hart's work, I think that it is essential to distinguish between knowing the meaning of a word, and being able to apply it correctly in any particular case. Meaning is what speakers share (it is the fulcrum of agreement and disagreement). It is something that a philosopher can hope to elucidate or clarify by pointing out what is important about

14 More precisely, the best conception will yield a determinate outcome in any case unless there is a tie (which is inconceivable) or unless the preinterpretive materials which a conception must fit are too meagre (which does not happen in any real legal system). For a recent discussion see Dworkin, 'Objectivity and Truth: You'd Better Believe It' (1996) 25 Philosophy and Public Affairs 87, 136-8.

15 The distinction Hart refers to is at (160); Hart discussed the same distinction in an introduction he wrote for Chaim Perelman, The Idea of Justice and the Problem of Argument (London: Routledge \& Kegan Paul 1963) vii at viii: '...justice is a concept of complex structure within which we should distinguish a constant formal element and a varying material element. This distinction might be presented in terms used in recent English moral philosophy as one between the constant definition of justice and the varying criteria for its application...'. 


\section{Herbert Hart and the Semantic Sting}

practices with which we are already familiar - though the elucidation itself may be controversial. Correct application may be controversial, and we should not expect that philosophers will be much help in resolving controversies about the application of words (they are, after all, just controversies about what is the case). Hart's theory needs some such distinction, if if is to give a satisfying account of the role of 'agreement in judgments'.

But it is very hard to see how Hart could have been working with the distinction between concepts and conceptions as Dworkin understood it, in spite of what Hart says in the Postscript. Dworkin has insisted that his distinction between concept and conception is 'very different' from the distinction between meaning and application ('extension'). ${ }^{16}$ His distinction is between a 'more abstract idea' and a 'particular substantive theory'. ${ }^{17}$ Even an uncontroversial statement about the concept of courtesy (Dworkin's example is that courtesy is a matter of respect) is interpretive and not semantic. In fact, it seems that even such an abstract statement may not be conceptual at all: Dworkin is careful not to say that it is conceptual, stating that it would be 'natural for people to regard' it as 'in the way of conceptual', ${ }^{18}$ and adding significant quotation marks to the claim that there is 'a "conceptual" connection between courtesy and respect'. ${ }^{19}$ Similarly, in Dworkin's theory, paradigms of courtesy are not conceptual, but have a 'kind of conceptual flavour'. ${ }^{20}$ Concepts, for Dworkin, are 'plateaus'. On the plateau, paradigms have a conceptual flavour, and statements that are abstract and uncontroversial enough will seem to be conceptual.

Dworkin's agile account of the distinction between concepts and conceptions does not support the association of concepts with meaning and of conceptions with application. In his usage, concepts and conceptions are just different levels at which more abstract and more concrete interpretive statements are made. Dworkin never says what the meaning of a word like 'courtesy' is. We could think of the concept of courtesy or the best conception of courtesy as giving the meaning of the word 'courtesy'. But if we think of the meaning of a word as 'linguistic ground rules everyone must follow to make sense' (the notion of meaning that Dworkin ascribes to criterial semantic theories), ${ }^{21}$ then neither a Dworkinian concept nor a Dworkinian conception can be equated with the meaning of a word. Perhaps, on Dworkin's understanding of the nature of rules, in the case of abstract concepts there is no such thing as 'linguistic ground rules everyone must follow to make sense'. That does not mean that such words have no meaning,

\footnotetext{
16 LE 71.

$17 \mathrm{Ib}$.

$18 L E 70$.

19 LE 71.

20 LE 72.

21 LE 71.
} 


\section{Herbert Hart and the Semantic Sting}

of course. Meaning just is the 'fulcrum of disagreement', and Dworkin's account of the interpretive process is itself, in part, an account of the meaning of abstract expressions.

To summarize, in Dworkin's view, the fulcrum of disagreement

lies in a shared set of paradigms and a shared understanding that application of the concept in question is to be governed by the best interpretation... of those paradigms. ${ }^{22}$

In Hart's view, the fulcrum of agreement is a shared set of paradigms, and a shared understanding that the word applies to those paradigms and to cases that are sufficiently similar in relevant respects.

There are two distinctive differences between these theories: their view of the relation between paradigms and the application of the concept in other cases (to Hart it is a relation of similarity; to Dworkin the relation is interpretive), and their view of the status of paradigms. I will address the second point, and ask whether paradigms can be ousted.

\section{Can paradigms be indisputable?}

Some paradigms are not so easily abandoned as men-rising-when-a-womanenters-the-room was abandoned as a paradigm of courtesy. Some paradigms have a very strong 'conceptual flavour', such as The Blue Danube as an example of music, or the Odyssey as an example of epic poetry, or the rack as an example of cruel punishment. ${ }^{23}$ It seems that no conception of epic poetry could account for other instances of the genre, if it excluded the Odyssey, and no conception of cruel punishment could account for other paradigms, if it claimed that the rack is not cruel. Dworkin's theory has resources to provide an account of such paradigms, but I will argue that no such account can do justice to their persistence.

Dworkin's theory could account for persistent paradigms as being particularly deeply embedded - as integrated members of groups of paradigms that are so significant that no acceptable holistic interpretation could 'isolate' them. But that approach would admit that those examples do not simply have a conceptual flavour, but are conceptual, so that anyone who knows the meaning of the phrase 'epic poetry', and is familiar with the Odyssey, knows that the Odyssey is an epic poem. If you only need to know the English language, and to be familiar with the rack, in order to know that the rack is a cruel punishment, then it seems that you do not need to interpret anything to

\footnotetext{
22 'Hart's Posthumous Reply', supra note 36, 14.

23 Cf. TRS 136 n.1: 'If the Court finds that the death penalty is cruel, it must do so on the basis of some principles or groups of principles that unite the death penalty with the thumbscrew and the rack.'
} 


\section{Herbert Hart and the Semantic Sting}

arrive at the judgment that the rack is cruel. ${ }^{24}$ You do not need to develop a conception of cruelty, you only need to grasp the concept.

So it seems that Dworkin's theory should account for persistent paradigms simply by maintaining the claim that a successful interpretation could conceivably show that any such object is not an instance of the concept in question. Conflicting, intuitively attractive notions militate for and against that claim: (1) After all, The Blue Danube is music, and no interpretation can show otherwise. (2) After all, we can understand someone who says that The Blue Danube is not music. It seems attractive to say that such a person is using the same concept as everyone else, and offering an (eccentric) interpretive claim. If their mistake were conceptual, how could we even understand them? They would not be speaking our language.

\section{Crazy Claims}

To sort out these conflicting notions, consider the following collection of crazy claims, which deny that concept-words of various kinds apply to objects that seem to be paradigms:

The Blue Danube isn't music, it's muzak.

The Odyssey isn't an epic poem-an epic has a hero who represents a race, or a nation. Odysseus is just one Greek, pitted against some Greeks and some gods.

The rack is not a cruel punishment-for a vicious crime. It's not cruel to do to the offender what the offender did to an innocent person.

The United States doesn't have a legal system; a legal system has rules and the United States just has lawyers.

David Copperfield isn't a novel, it's an autobiography.

Pele wasn't a soccer player, he was an artist.

I'm not bald, I just have removable hair.

He may not be married, but he's no bachelor.

The sky is not blue. You haven't seen blue until you've seen a sapphire.

These crazy claims seem to pose a dilemma for Hart. Consider the claim about The Blue Danube. From Hart's point of view, that seems to be a claim that $x$ is not $\mathrm{F}$, where the concept of $\mathrm{F}$ can be elucidated by pointing out salient features of (e.g.) $x$. So the claim seems to be nonsense. In fact, all the claims in the list seem to be nonsense. But that can't be right: nonsense is meaningless, and these claims are all too meaningful. We can understand them perfectly well. They are false (or they combine true claims with false claims), but they are not nonsense.

24 I do not mean that you can know English, or the meaning of the word 'epic', without knowing anything else. 


\section{Herbert Hart and the Semantic Sting}

We can imagine theories that arrive at the crazy claims. That very fact seems to make the case for an interpretivist semantic theory (in fact, it seems to extend the interpretivist claim to all words, including words for which Dworkin would adopt a criterial semantics, like 'bachelor' and presumably 'bald'). The fact that we can conceive of theories that reach the conclusions in the list suggests that, if we are to contradict any of the crazy claims, what we need to do is to develop a better theory. Of course, the theories that yield the crazy claims are bad theories-but that is no problem for interpretivism. The interpretivist claim still seems to be made out: we can only conclude that each of the claims is wrong by working out theories that compete with the faulty theories, and that succeed by showing that those theories give unsatisfactory accounts of the concepts in question.

But what is the flaw in, e.g., the theory of epic poetry that concludes that the Odyssey is not an epic poem? The flaw is that it is not a theory of epic poetry. Perhaps the theorist is making a striking claim for rhetorical effect, to draw attention to a feature of some epics that is especially intriguing-perhaps to claim that the Odyssey lacks a feature that is distinctive of much of the epic tradition. But there is just no prospect that a better interpretation of that tradition could eject the Odyssey from the material that an interpretation of epic poetry must give an account of. That does not mean that people will not start excluding the Odyssey from what they call 'epic poetry' tomorrow. It means that, if they do so, they will not be using the concept of epic poetry that we have today.

Dworkin's theory has the equipment to give a rather similar account of the crazy claims - but an account that reaches different conclusions about paradigms. Dworkin distinguishes between eligible and ineligible interpretations, ${ }^{25}$ between hard and easy cases, ${ }^{26}$ and between questions on which a statute is clear (so that, we might say, a decision contrary to the clear meaning would not be giving effect to the requirements of the statute) and cases on which it is unclear. ${ }^{27}$ A decision is based on an ineligible interpretation when it does not meet the 'rough threshold requirement' of fit 28 (that is, when it lacks 'textual integrity' ${ }^{29}$ ), or when it does not present 'any competent justification'. ${ }^{30}$ Dworkin's account portrays people who make the crazy claims as perfectly competent speakers of the English language, whose theories still count as theories of the concepts they purport to interpret, but are ineligible because they ignore the interpretive requirements of integrity. The conclusion that they fail to oust the paradigms they attack is an interpretive conclusion.

\footnotetext{
$25 L E 255$.

$26 \mathrm{Ib}$.

27 LE 351-3.

28 LE 255.

29 LE 338-340.

30 LE 339.
} 


\section{Herbert Hart and the Semantic Sting}

The issue, it seems, is how to describe what is going on when people make the crazy claims. Are they best described as not giving a theory of music etc. (as Hart might say)? Or as giving bad theories of music, etc.- - so bad that we can call them ineligible (as Dworkin might say)?

There are two related considerations in favour of the first description:

1. The crazy claims are nonsense, in a sense. People who make those claims could very well understand the English language. But people who understand English do lots of things with it, and the people who make these claims are using it to talk nonsense. Nonsense is not necessarily meaningless, or self-contradictory-it may only be absurd. The crazy claims are all instances of a useful and common rhetorical figure, in which the speaker withholds a term from an object to which it clearly applies. So they can be explained as parasitic uses of concepts. If $x$ is clearly an $\mathrm{F}$, then saying that $x$ is not an $\mathrm{F}$ can be a usefully hyperbolic way of saying that $x$ is a pre-eminent F (Pele), or a bad F (The Blue Danube), or not just an F, or not the only F.... ${ }^{31}$ When we read each claim, the first half just seems silly, but when we read the second half we see the point. The claims are figurative ways of saying such things as that the concept is too good for the object, or that the object is too good for the concept. It is the indisputability of the paradigms disputed by the crazy claims that gives those claims their ironic or dramatic impact. Such claims would not have the meaning that they have, if they were not disputing the indisputable - if the paradigms they attack were not secure from challenge.

2. The interpretivist can describe the people who make the crazy claims as linguistically competent, but so can Hart. We have already seen that The Concept of Law does not claim to state rules for the use of words. If Hart does not have a criterial semantic theory, then obviously he does not claim that there are shared rules in the form of criteria- or so I claimed in the discussion of the anthropologist who visited Freedonia.

However, the crazy claims are different from the anthropologist's use of the phrase 'legal system': she did not deny, e.g., that the United States has a legal system; she only applied the phrase to a social order that does not share the features of paradigm legal systems that Hart identified as salient. So what about the proposition that things like Pele count as soccer players? Doesn't Hart think that that is a rule for the use of the term 'soccer player'? If Hart thinks that paradigms are indisputable cases on which there must be general

31 Note that Hart begins The Concept of Law with some crazy claims about law (from Llewellyn, Holmes, Gray, Austin and Kelsen; $C L$ 1). He does not dismiss them as senseless - he describes them as seeming 'strange and paradoxical', and says that 'such statements are both illuminating and puzzling: they are more like great exaggerations of some truths about law unduly neglected, than cool definitions.' ( $C L 2)$. 


\section{Herbert Hart and the Semantic Sting}

agreement if communication is to be possible, how can the people who make the crazy claims be speaking English?

Perhaps Hart could say that agreement in paradigm cases must be general for communication to be possible, but it need not be absolute. If someone made crazy claims about every clear case of the application of every concept, communication with that person would become, if not impossible, rather strained. And if many people did so, there would not be any clear cases. But there is plenty of latitude in human communication-more latitude, no doubt, than Hart pointed out. People do not stop talking English, and do not become unintelligible, when they start talking nonsense. People are surprisingly intelligible. Lawyers in particular ought to be aware that people are capable of disputing the indisputable. So the fact that people can make crazy claims does not mean that the claims are interpretations of the concepts they purport to interpret.

But there is more to say than Hart said: Dworkin has pointed out that objects that appear to be paradigms (understood as clear examples of the application of the expression, which are useful in explaining the meaning of the expression) can sometimes be eradicated. The difficult task is to make claims of the right level of generality. Dworkin's theory overgeneralises when it claims that no paradigm of an abstract concept is secure from challenge. Perhaps a theory that claims that there are ineradicable paradigms of any genuine concept would also overgeneralise. ${ }^{32}$ Of course, 'paradigm' is only a technical term, and we could define 'paradigm' as an ineradicable instantiation of a concept (so that ostensible paradigms that have to be eradicated are simply not genuine paradigms). Contrary to what Dworkin's theory suggests, that is a definition that would make perfect sense, even for concepts that he calls interpretive. But we would not be able to offer criteria for identifying such things, and there may be many items concerning which we would encounter considerable doubt and disagreement as to whether they are paradigms in that sense. 'Paradigm' in that sense would not be meaningless, and it would have genuine application, but it would be vague. Some paradigms (in the sense of examples that people find useful in explaining meaning) can be ousted and some cannot be ousted by a theory of the concept, and the distinction is not sharp.

We can make another important point about how general a claim can be made concerning the ineradicability of paradigms: the concepts of music, cruel punishment, a legal system and so on (which Dworkin calls abstract) are certainly more interesting, complex, debatable and evaluative than 'bald' or 'bachelor' or 'blue' (words of the sort for which Dworkin proposes a criterial semantics. But they are similar in this respect: there are indisputable

\footnotetext{
32 Perhaps Andrei Marmor does so, in formulating a view he ascribes to Hart: 'Since the meaning of a concept-word consists in (inter alia) its use, there must always be standard instances in which the application of the concept word is unproblematic.' Interpretation and Legal Theory (Oxford: Clarendon, 1992) 126; cf. 134-35.
} 


\section{Herbert Hart and the Semantic Sting}

paradigms of the application of both sorts of words. The meaning of any of these words can be conveyed by pointing out paradigms and saying 'things like this are....' So the claim that there are indisputable paradigms can be made about a very wide variety of expressions.

This claim should not be applied hastily to concepts in general, however. Dworkin's refusal to offer a unified theory of the application of words shows a very healthy caution. When it comes to explaining the role of paradigms in the use of very abstract evaluative expressions like 'good' and 'right', I think that everyone should tread carefully. Perhaps those expressions create difficulties both for Hart, and for Dworkin's interpretive theory. The general problem is that meaningful disagreement about the application of such words can be more pervasive than meaningful disagreement about the application of words like 'music'. For Hart's theory, the problem is that in many contexts, speakers may not share the view that anything is a paradigm for the application of 'good' or 'right' - and yet their disagreements may be genuine (they all know what 'good' means). For Dworkin's theory, the problem is that the use of 'good' and 'right' seems not to be interpretive. In many contexts (in fact, in any context that is not dominated by the associative obligation to participate in a community of principle), speakers deciding whether such an expression applies may not seek to achieve fit with their community's practice of calling things 'good' or 'right'. And they may be right not to seek such a fit.

The challenge for both theories is to say something sensible about what form and extent of agreement people need in order to use words like 'good' meaningfully. That is, they need to say something sensible about the fulcrum of agreement and disagreement for abstract expressions.

I cannot address that challenge here, and this is not the place to claim that neither Hart nor Dworkin can give an account of very abstract evaluative concepts. ${ }^{33}$ I will restrict myself to a claim about classifying terms of the sort that are used in our list of crazy claims (and very commonly in legal standards). I propose that the ineligibility of the crazy claims is misdescribed as the outcome of a theory: the conclusion that they are ineligible cannot be the outcome of a theory, if any alternative theory would be a theory of something other than music or epic poetry.... And by the same token, a claim that David Copperfield is a novel, or a claim that the rack is a cruel punishment, is misdescribed as the successful outcome of a theory of the novel or a theory of punishment.

That view is compatible with a great deal of genuine theoretical disagreement about the requirements of the law. Law's Empire shows how disagreement can go deeper than a criterial theory would allow. But disagreement can go deeper than a competition between conceptions: people can have genuine disagreements not just about conceptions, but about the concept of, e.g., law. Hart and Dworkin do not simply offer competing

33 They both set out to do so for the concept of justice, at CL 159ff. and LE 73-76. 


\section{Herbert Hart and the Semantic Sting}

conceptions of law - they disagree about the concept. ${ }^{34}$ Of course, people can even disagree about the nature of concepts themselves. The crazy claims can actually be sincere.

\section{4. 'Pivotal cases' - a test for the notion of paradigms}

To counter what he calls the "sophisticated" or 'borderline-case' defence of legal positivism, Dworkin proposes that genuine legal disputes can arise not only in borderline cases, but also in 'pivotal cases'. ${ }^{35}$ A pivotal case concerning the application of an expression is one which each side in a dispute claims is a clear case. Presumably most legal disputes over the application of an expression are pivotal cases, since litigants do not commonly argue that they have a borderline case.

Dworkin argues that pivotal cases must be something different from (and less trivial than) borderline cases of the application of vague language. But the most mundane vague expressions can yield pivotal cases. You and I might agree that someone is a borderline case for, e.g., 'bald' or 'tall', and disagree about how to draw the line. Or you could think they are clearly tall, or clearly bald, and I could think they are clearly not tall, or clearly not bald - even though we both speak English. When we engage in either form of dispute, 'borderline' or 'pivotal', we are differing about whether the person in question is sufficiently similar in relevant respects to paradigms of tallness or baldness. ${ }^{36}$ And that suggests that Hart need not deny that there are pivotal cases. Consider Dworkin's example of a dispute over a pivotal case-whether photography is an art form:

One group argues that (whatever others think) photography is a central example of an art form, that any other view would show a deep misunderstanding of the essential nature of art. The other takes the contrary position that any sound understanding of the character of art shows photography to fall wholly outside it, that photographic techniques are deeply alien to the aims of art. It would be quite wrong in these circumstances to describe the argument as one over where

\footnotetext{
34 I think that this claim about their debate is consistent with what Dworkin says about the nature of concepts, since 'the contrast between concept and conception is ... a contrast between levels of abstraction at which the interpretation of the practice can be studied' (LE 71). 'Political philosophy thrives... in spite of our difficulties in finding any adequate statement of the concept of justice.' ( $L E 93)$. He implies that we could say the same about the concept of law.

35 LE 39-43.

36 So we could not have a 'pivotal' dispute about whether someone with no hair is bald, or about whether someone 7'6" tall is tall. I could still disagree with you even in a paradigm case, however, by making a crazy claim. There is no sharp distinction between pivotal disputes and disputes in which one party is making a crazy claim.
} 


\section{Herbert Hart and the Semantic Sting}

some borderline should be drawn. The argument would be about what art, properly understood, really is; it would reveal that the two groups had very different ideas about why even standard art forms they both recognize - painting and sculpture - can claim that title. (LE 42)

Perhaps we can view these claims as a potent argument against criterial semantics - against the view that the dispositions of speakers determine the correct application of the word 'art'. But nothing in Dworkin's scenario conflicts with Hart's claims about language. All Hart claims is what Dworkin suggests - that the debate makes sense because there are standard art forms.

There are paradigms of art-such as painting and sculpture-and I can elucidate the concept of art by pointing out what is salient about those paradigms. That task of elucidation will require me to make controversial claims about what is salient, and it may require me to make controversial judgments as to whether (e.g.) photography is art. What the task will not require me to do is to conclude whether, in the final analysis, painting and sculpture really are forms of art. It is not just that the conclusion is easy to reach. It is that the propositions that painting is an art form or that sculpture is an art form are not conclusions. When people talk about art forms, they are talking about things like painting and sculpture, and there is nothing I can do to change that. Of course, I can deny that painting is an art form. My crazy claim will be intelligible, and it might conceivably be a useful way of getting some point across. Or I can just decide to use the phrase 'art form' to mean something other than art form. Those possibilities tell us nothing about the meaning or application of the expression 'art form'. They just remind us of the variety of things that people can do with language.

\section{Conclusion}

An account of the use of language should dissent from two elements of Dworkin's semantic theory: the claim that no paradigm of an abstract concept is secure, and the claim that vagueness is a semantic defect of words like 'bald', and is not a feature of words like 'courtesy' or 'cruel'.37 Accepting these claims does not commit anybody to a criterial semantics; if I am right, it is very important in understanding Hart to see that he was not offering a criterial semantic theory.

For at least some abstract concepts, we should accept that some paradigms are indisputable instances, just as it is indisputable that a person with no hair is bald. That does not mean that The Concept of Law is the last word on the

\footnotetext{
${ }^{37}$ See, e.g. $L E$ 17. This claim becomes important in assessing Dworkin's theory if there is no answer to some questions of the application of vague expressions. For an argument to that effect (and a brief discussion of Dworkin's claim that abstract concepts are not vague), see Endicott, 'Vagueness and Legal Theory' 3 Legal Theory 37 (1997).
} 
Herbert Hart and the Semantic Sting

meaning of language: my argument has partly been that Hart said very little about it. Dworkin has pointed out the important fact that some cases that appear to be paradigms of some concept (even cases that everyone has always treated as paradigms) may not in fact be instances of the concept at all. And there is no sharp distinction between ostensible paradigms that can be ousted in that way, and paradigms that cannot be ousted. If people can have pivotal disagreements, it seems that what Hart vaguely called 'open texture' is more than a matter of a fringe, margin or periphery. These insights are not inconsistent with Hart's semantic views. But they add important elements. 